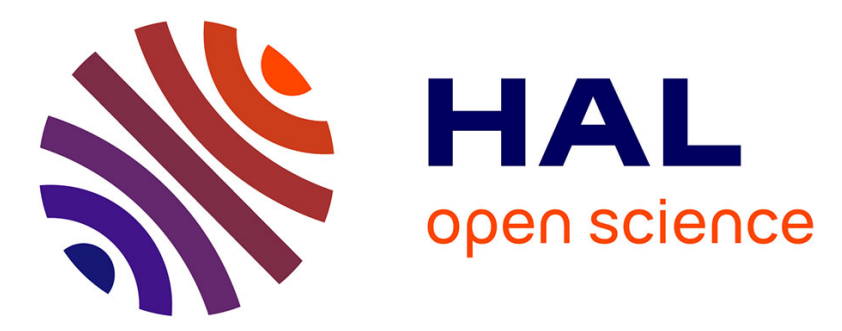

\title{
Consciousness, unconsciousness and death in the context of slaughter. Part II. Evaluation methods
}

Claudia Terlouw, Cécile Bourguet, Véronique Deiss

\section{To cite this version:}

Claudia Terlouw, Cécile Bourguet, Véronique Deiss. Consciousness, unconsciousness and death in the context of slaughter. Part II. Evaluation methods. Meat Science, 2016, 118, pp.147-156. 10.1016/j.meatsci.2016.03.010 . hal-02634941

\section{HAL Id: hal-02634941 \\ https://hal.inrae.fr/hal-02634941}

Submitted on 27 May 2020

HAL is a multi-disciplinary open access archive for the deposit and dissemination of scientific research documents, whether they are published or not. The documents may come from teaching and research institutions in France or abroad, or from public or private research centers.
L'archive ouverte pluridisciplinaire HAL, est destinée au dépôt et à la diffusion de documents scientifiques de niveau recherche, publiés ou non, émanant des établissements d'enseignement et de recherche français ou étrangers, des laboratoires publics ou privés. 
Review

\title{
Consciousness, unconsciousness and death in the context of slaughter. Part II. Evaluation methods
}

\author{
Claudia Terlouw ${ }^{\mathrm{a}, \mathrm{b}, *}$, Cécile Bourguet ${ }^{\mathrm{c}}$, Véronique Deiss ${ }^{\mathrm{a}, \mathrm{b}}$ \\ a INRA, UMR1213 Herbivores, 63122 Saint-Genès-Champanelle, France \\ b Clermont University, VetAgro Sup, UMR1213 Herbivores, BP 10448, 63000 Clermont-Ferrand, France \\ c Bureau E.T.R.E., Bravant, 63210 Olby, France
}

\section{A R T I C L E I N F O}

\section{Article history:}

Received 4 September 2015

Received in revised form 4 March 2016

Accepted 9 March 2016

Available online $\mathrm{xxxx}$

\section{Keywords:}

Slaughter

Consciousness

Unconsciousness

Death

Stunning

Bleeding

Animal welfare

\begin{abstract}
A B S T R A C T
This second review describes indicators of consciousness and unconsciousness that can be used in the abattoir. These indicators evaluate different aspects of cerebral functioning, but only indirectly. It is therefore necessary to monitor several indicators. Animals are considered unconscious if signs of consciousness are absent, and signs of unconsciousness are present. Given that the unconscious state may be reversible it is further necessary to monitor these indicators until the end of bleeding. The techniques used to diagnose brain death in humans cannot be used in the slaughterhouse. Under field conditions, at the end of bleeding, the absence of breathing and of brainstem reflexes and the adequacy of the exsanguination are verified. If these three aspects are confirmed, in the context of the slaughterhouse and at this stage of the slaughter process the loss of vital functions is irreversible and the animal can be considered dead.
\end{abstract}

(c) 2016 Elsevier Ltd. All rights reserved.

\section{Contents}

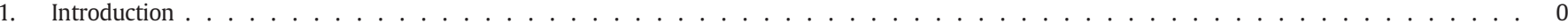

2. Indicators of consciousness and unconsciousness $\ldots \ldots \ldots \ldots$

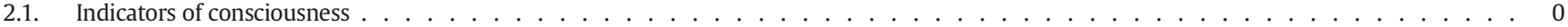

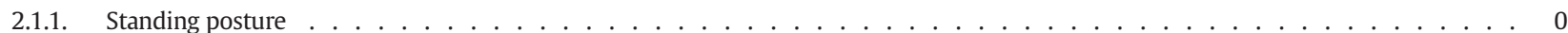

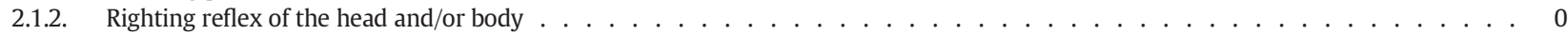

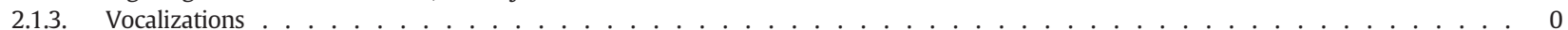

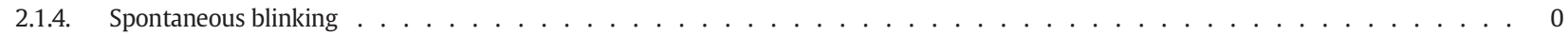

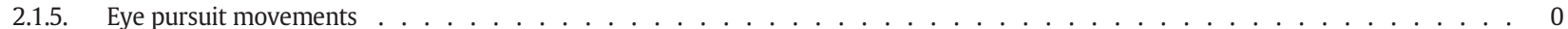

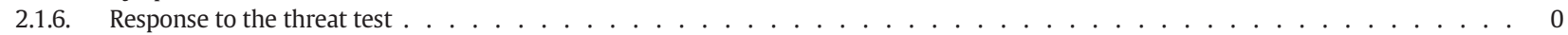

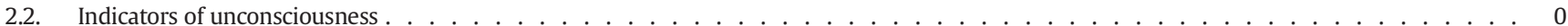

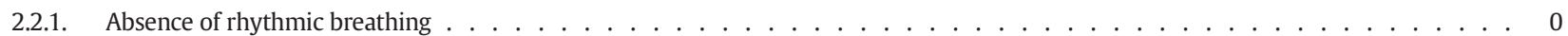

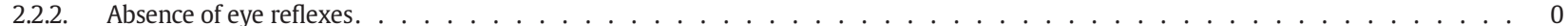

2.3. Indicators with low discriminatory power or needing further development $\ldots \ldots \ldots \ldots$

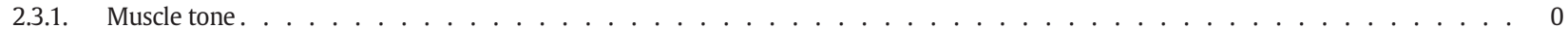

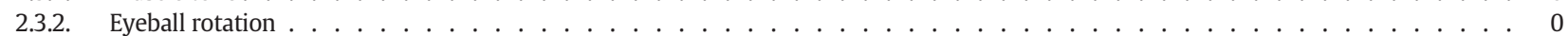

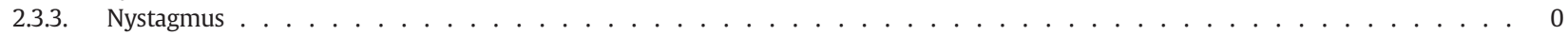

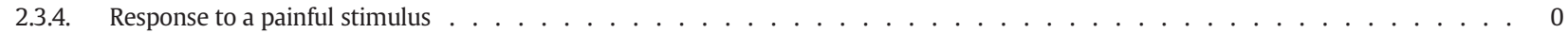

2.3.5. Response to sensory stimuli other than threat or pain . . . . . . . . . . . . . . . . . . . . . 0

2.3.6. Apparently spontaneous neck or leg movements after stunning . . . . . . . . . . . . . . . . . . . . . . . . . 0

3. Relationships between the different indicators. . . . . . . . . . . . . . . . . . . . . . . . . . . . . . . 0

4. Estimated delay until brain death in the slaughter context . . . . . . . . . . . . . . . . . . . . . . . . . . . . . 0

\footnotetext{
* Corresponding author at: INRA, UMR1213 Herbivores, 63122 Saint-Genès-Champanelle, France.

E-mail address: claudia.terlouw@clermont.inra.fr (C. Terlouw).
} 


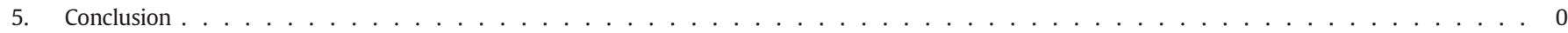

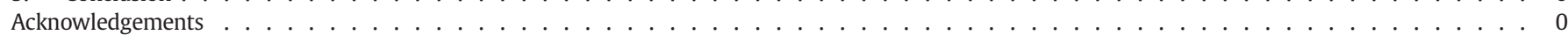

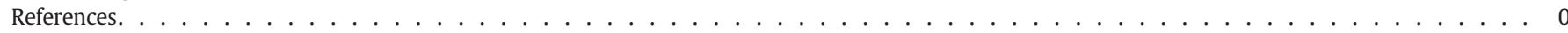

\section{Introduction}

Our first review presented the current state of scientific knowledge on brain functioning in the context of unconsciousness and the process of death at slaughter (Terlouw, Bourguet \& Deiss, 2016). Loss of consciousness is the result of a reversible or irreversible dysfunction of certain brain structures: the reticular formation, the ascending reticular activating system or the cerebral hemispheres globally. The death of an individual is defined in terms of brain death. This implies the irreversible cessation of brain structures responsible for vital functions like breathing and thermal and cardiovascular regulation that are in the brainstem (Laureys, 2005). This second review aims to contribute to the reflection on the use and interpretation of indicators of consciousness and unconsciousness. The difficulty of assessing brain death in the context of slaughter is also addressed. The synthesis concerns the major food species consumed in Europe, with the exception of fish.

\section{Indicators of consciousness and unconsciousness}

Following stunning, to avoid unnecessary stress or pain, the unconscious state should be ensured before shackling and hoisting of cattle, pigs and sheep (Grandin, 2013). A number of indicators are used to assess the state of consciousness or unconsciousness of the animal (EFSA, 2004, 2013). These clinical signs are indirectly associated with brain functions involved in consciousness, particularly the reticular formation and/or the cerebral cortex. Some of these indicators indicate almost certainly a conscious and others an unconscious state (Table 1). To ensure unconsciousness, indicators of consciousness must be absent and indicators of unconsciousness must be present. The absence or presence of these indicators must be checked after stunning and during bleeding, for both conventional and religious slaughter. Other indicators have a lower discriminating power and can be used as complementary information (Gregory, Lee, \& Widdicombe, 2007). The relationships between the different indicators and brain functioning, including consciousness and unconsciousness, are discussed below.

\section{Table 1}

Indicators of consciousness and unconsciousness ${ }^{\mathrm{a}}$. Other indicators may be used but their discriminatory power is lower. As the indicators are only indirectly related to the state of consciousness, it is necessary to check several. The animal is unconscious when the signs of consciousness are absent and signs of unconsciousness are present.

\begin{tabular}{ll} 
Indicator & Sign of \\
\hline Standing posture & \\
Head or body righting reflex & Consciousness \\
Voluntary vocalizations & \\
Spontaneous blinking & \\
Eye pursuit & \\
Response to the threat test & Unconsciousness or death \\
\hline Absence of corneal reflex & \\
Absence of eyelash reflex & \\
Absence of rhythmic breathing &
\end{tabular}

a Some indicators are explicitly mentioned in the memorandum of the French Ministry of Agriculture DGAL/SDSSA/N2012-8250 of 05 December 2012, based on Council Regulation No. 1099/2009: Operators must carry out systematic checks to ensure that animals do not show any sign of life before undergoing dressing or scalding.

According to this memorandum, the clinical signs to check are:- Lack of pupillary reflex;Absence of corneal reflex;- Absence of spontaneous breathing.

\subsection{Indicators of consciousness}

\subsubsection{Standing posture}

In the slaughter context, the standing posture is an indicator of consciousness (Table 1 ). Therefore, the immediate and permanent loss of the standing posture is used as an indicator of the potential loss of consciousness. Immediate collapse following application of the stun is a main indicator because it is relatively visible; it allows assessing the quality of the stun or of bleeding in non-stunned animals that are bled in the standing posture. This indicator should be interpreted with caution, however, because collapse can be caused by an inability to stand, for example, when the stun gun is placed in the neck and severs the upper spinal cord only paralysing the animal without damaging the brain. Moreover, the collapse cannot be evaluated in animals maintained in a box which restrains the head or body, in a V-shaped restrainer, or animals suspended on a rail (poultry).

Following an effective mechanical stunning the animal collapses immediately. This collapse can be explained by damage to the reticular formation, involved in the control of the standing posture (Purves et al., 2001; Schepens \& Drew, 2004). Electrical stunning also causes immediate collapse, due to the seizure spreading through the cerebral hemispheres and subcortical structures, particularly the reticular formation (Tatum, 2010). Gas stunning and bleeding without stunning gradually induce a loss of capacity to maintain the standing posture probably due to a global progressive dysfunction of cortical and subcortical structures including the reticular formation.

Widespread anoxia in the brain following bleeding of non-stunned animals results also in a global progressive dysfunction of cortical and subcortical structures explaining the progressive loss of the capacity to stand upright. It was suggested that the first loss of posture may be only a sign of the early stages of onset of unconsciousness (Gibson, Dadios, \& Gregory, 2015; Gregory, Fielding, von Wenzlawowicz, \& von Holleben, 2010). This may explain why in some cases, during religious slaughter some cattle can regain the standing posture briefly, probably due to transient physiological adjustments partly restoring neurological function, before the final collapse (Bourguet, Deiss, Tannugi, \& Terlouw, 2011; Gregory et al., 2010).

\subsubsection{Righting reflex of the head and/or body}

An animal on the floor that is conscious following an unsuccessful stun may attempt to lift the head and/or body, or at least to position them in the usual angle (head/body axis perpendicular to the axis of the earth; Anil, 1991). After an effective stun, as long as the animal is unconscious, it does not attempt to recover its normal posture. Recovery movements are oriented but sometimes difficult to distinguish from other movements which are automatic or reflex movements (see below: paddling and other movements).

\subsubsection{Vocalizations}

When unrelated to social communication, vocalization expresses most often pain (Grandin, 2013). It was found that 99\% of the vocalizations of cattle and pigs during slaughter were preceded by aversive situations, such as the use of an electric prod, a fall, a failed stun or excessive pressure during restraint (Grandin, 1998; Warriss, Brown, Adams, \& Corlett, 1994; Watts \& Stookey, 2000; White et al., 1995). As pain can only be perceived if the animal is conscious, intentional vocalizations occurring after a stun are indicative of consciousness (Grandin, 2013). Some guttural sounds are reflex-like that should not be confounded with vocalizations (see below: gasping). 


\subsubsection{Spontaneous blinking}

Spontaneous blinking involves circuits in the brainstem and in the cortex, that are partly the same as those involved in the corneal blink reflex that will be discussed below (Bour, Ongerboer de Visser, Aramideh, \& Speelman, 2002; Morcuende, Delgado-Garcia, \& Ugolini, 2002). Spontaneous blinking is considered as an indicator of consciousness (Grandin, 2013), but further studies are required to know their exact relationship with the level of consciousness. For example, in a study involving 20 bulls, none showed a corneal reflex after stunning, suggesting a state of unconsciousness, but 3 presented spontaneous blinking (Terlouw, Bourguet, Deiss \& Mallet, 2015).

\subsubsection{Eye pursuit movements}

Eye pursuit movements aim to track moving stimuli in the visual field. Following an effective mechanical or gas stun, the eyes are open with eyelids and eyeballs immobile (Grandin, 2013). After an effective electrical stun, the eyes are initially closed, then reopened. The eyelids and eyeballs are immobile (Grandin, 2013). Eye pursuit movements are considered a sign of consciousness because they involve not only different structures in the brainstem but also in the cortex (Enderle, 2000; Tehovnik, Sommer, Chou, Slocum, \& Schiller, 2000). While the presence of eye pursuit movements is considered indicative of the presence of consciousness, the absence of eye movements does not necessarily indicate unconsciousness (Table 1). In one study, humans were asked to determine the movements of a pendulum while a neck pressure was exerted to stop the cerebral circulation. The eyeballs remained fixed in the centre of the eyes about $1 \mathrm{~s}$ before consciousness was lost as indicated by the presence of delta waves in the EEG. Questioned later, the subjects said they were still conscious but unable to move their eyes (Rossen, Kabat, \& Anderson, 1943).

\subsubsection{Response to the threat test}

To test the response to a threat stimulus, a finger or the hand is moved rapidly towards the eye of the animal and the presence of a blinking response or withdrawal reaction is checked (Limon, Guitian, \& Gregory, 2010; Verhoeven, Gerritzen, Kluivers-Poodt, Hellebrekers, \& Kemp, 2015b; Verhoeven, Hellebrekers, Gerritzen, \& Kemp, in press). To conduct the test properly, it must be ascertained that the animal has adequate vision (e.g. no eyeball rotation or nystagmus, no blood in the eyes). The response involves higher-order brain mechanisms, including cortical functions to integrate the information coming from the environment (Liu \& Ronthal, 1992). The relationship between threat test and consciousness was shown in sheep and calves as the reflex was lost several seconds before unconsciousness was reached (Verhoeven et al., 2015b; 2016). In a group of more than 300 cattle having undergone puntilla and of which $82 \%$ showed rhythmic breathing, $61 \%$ showed a response to the threat stimulus (Limon et al., 2010), suggesting a potential good sensitivity of the test, but also that it needs to be associated with other tests. More research is needed, including different contexts and species.

\subsection{Indicators of unconsciousness}

\subsubsection{Absence of rhythmic breathing}

Following the stun, an animal that breathes may be unconscious, but an animal that has stopped breathing is unconscious or dead (Verhoeven, Gerritzen, Hellebrekers, \& Kemp, 2015a). The presence of rhythmic breathing after stunning is an indication to proceed with a second stunning (Grandin, 2013). The respiratory muscles are innervated by control centres located in the medulla oblongata, located in the lower part of the brainstem. These centres consist of different groups of neurons controlling either inspiration or expiration. These groups of neurons are activated alternately and thus form a neurological network underlying rhythmic breathing. They are stimulated by the reticular formation that receives information from the periphery and higher brain centres (Siegel \& Sapru, 2006; Silbernagl \& Despopoulos, 2003).
Gasping corresponds to intermittent, rather forceful inspiratory movements which are not organised in the same manner as normal breathing and can be induced by ischaemia or hypoxia (St John, 2009). Gasping reflects the dysfunction of brain centres in the pons and recruits medullary mechanisms (St John, 2009). Gasping precedes death and should not be confused with rhythmic breathing. It is often accompanied by guttural sounds that should not be confused with vocalizations. Gasping has been observed in a captive bolt stunned calf whose EEG had been isoelectric for $60 \mathrm{~s}$ (Blackmore \& Newhook, 1982).

Following a successful mechanical stun regular breathing movements are absent. Following bleeding of non-stunned animals, rhythmic breathing changes progressively into irregular breathing (alternation of shallow breathing, gasping, rapid shallow breathing, transient apnoeas; Verhoeven et al., 2015b). Some consider that the presence of gasps is indicative of a bad stun if mechanical stunning was used, but that some gasping may be observed after a successful electrical stun (Grandin, 2013). Gasping may also be a first indication of recovery following gas stunning (Atkinson, Velarde, Llonch, \& Algers, 2012). The cessation of breathing due to a mechanical stun can be explained by the dysfunction of the reticular formation or the medulla. The cessation of breathing after gassing $\left(\mathrm{CO}_{2}\right.$ overload/lack of $\left.\mathrm{O}_{2}\right)$ is explained by a slowing of neuronal activity of the hemispheres and brainstem. Following electrical stunning, spreading of the epileptic seizure to subcortical regions (thalamus, brainstem), and certain cortical areas can cause respiratory arrest (Kaada \& Jasper, 1952; Devinsky, 2004). Involuntary muscle contractions, including those involved in breathing, contribute to the effects of the epileptic seizure on breathing. In general, the absence of breathing causes anoxia in the brain and thus contributes to the state of unconsciousness.

\subsubsection{Absence of eye reflexes}

In principle, following the stun, an animal presenting eye reflexes may be unconscious, but an animal that does not present them is unconscious or dead (Table 1 ). The presence of eye reflexes after stunning is an indication to proceed with a second stun (Grandin, 2013). However, as will be indicated below, to carry out the test and interpret the result correctly, several considerations should be taken into account.

The corneal reflex is tested by lightly touching the cornea. ${ }^{1}$ The reflex involves the transmission of sensory information to the brainstem eliciting a motor response: if present, the eyeball is slightly retracted and the eyelid closes. The sensory information passes through the trigeminal nerve to reach the trigeminal nucleus next to the reticular formation (Cruccu \& Deuschl, 2000). It is connected with the facial nucleus to stimulate the facial motor nerve which allows closing the eyelid. The trigeminal nucleus has a further input to the abducens and accessory abducens nuclei which are involved in the retraction of the eyeball in its socket (Delgado-Garcia et al., 1990). The connections between the trigeminal and facial nuclei pass through the reticular formation (Aramideh \& Ongerboer de Visser, 2002; Dauvergne et al., 2004).

In the slaughter context, the corneal reflex is considered the most reliable eye reflex to evaluate the state of unconsciousness. Any interruption of the underlying neural circuit will cause the modification or the absence of the reflex. The neural circuit of the corneal reflex crosses the reticular formation. If the corneal reflex is absent, there is a large probability that the disruption is associated with a wider dysfunction, comprising part of the reticular formation, and thus with a state unconsciousness (Cruccu, Leardi, Ferracuti, \& Manfredi, 1997; Kimura \& Lyon, 1972; Laureys, 2005; Sturges, 2005; Zerari-Mailly, Dauvergne, Buisseret, \& Buisseret-Delmas, 2003). For this reason, the absence of the corneal reflex is considered a fairly reliable indicator of unconsciousness.

The absence of the corneal reflex should be associated with other indicators of unconsciousness because there are exceptions. For example,

${ }^{1}$ When eliciting the corneal reflex, care should be taken that the response was elicited by touch rather than by the sudden movement towards the eye, i.e. the threat test (cf below; Blumenfeld, 2002). 
very small, focal lesions ${ }^{2}$ can abolish the corneal reflex, at least unilaterally, without inducing unconsciousness (Ongerboer de Visser \& Kuypers, 1978). This situation is, however, unlikely in the context of stunning or bleeding without stunning. On the opposite, dysfunction of the reticular formation at a remote distance from the neural circuit of corneal reflex, or interruption of the ascending reticular activating system can both induce a state of unconsciousness without abolishing the corneal reflex. For this reason an unconscious animal can present a corneal reflex, including at slaughter. For example, in a study on pigs, returns of the corneal reflex were observed on average $37 \mathrm{~s}$ after electrical stunning. At this stage, in most slaughterhouses, bleeding is in progress and the animals are unlikely to be conscious (McKinstry \& Anil, 2004; Vogel et al., 2011). Accordingly, in these studies, the return of the corneal reflex was not associated with a return of other signs, such as breathing, confirming that the animal was still unconscious (McKinstry \& Anil, 2004; Vogel et al., 2011).

A temporary return of the corneal reflex is possible in the context of slaughter without stunning (Bourguet et al., 2011). These returns can be explained by different phenomena. As mentioned above ("standing posture"), physiological changes may restore sufficiently functionality of neurons to allow a temporary recovery of the reflex (Gregory et al., 2010). These signs are not necessarily indicative of a partial or total return of consciousness but leave a doubt (Bourguet et al., 2011; Gregory et al., 2010). Second, under certain circumstances the reflex cannot be tested correctly and the apparent initial absence of a reflex may simply be due to a misinterpretation of the result. Particularly, in the case of strong eye muscle contraction it is impossible to carry out the test correctly. This may the case in religious slaughter or slaughter by puntilla, where bovine eye muscles may contract after the start of the bleeding. This contraction prevents closing of the lid in response to stimulation of the cornea and the reflex appears absent but the animal may be conscious. Incidentally, this contraction often causes the eyeball to rotate, making it impossible to reach the cornea and therefore to carry out the test (Limon et al., 2010; Terlouw et al., personal observations). Similarly, to check a classical corneal reflex after electrical stunning, it is necessary to wait because the animal is in a tonic state and the reflex is blocked (Grandin, 2013). Subsequently, the animal is in a clonic state characterized by vigorous movements, such as paddling or wing flapping, but the eye muscles may also be involved, again making it difficult to carry out the test correctly (Grandin, 2013). Finally, it may be difficult, however, to carry out the corneal reflex when the animal has blood in the eyes, as may occur during bleeding.

The palpebral reflex can be tested by a light touch of the eyelid and the eyelash reflex by lightly brushing the eyelashes. The responses are the same, eyelid closure, and at least for the palpebral reflex the neural circuit is largely similar to that of the corneal reflex. At least under certain conditions, the palpebral reflex appears less resistant than the corneal reflex as in cattle bled without stunning the palpebral reflex was lost before the corneal reflex (Bourguet et al., 2011; Verhoeven et al., 2016). The eyelash reflex is considered unreliable for the assessment of the effects of certain pharmacological anaesthesia (Vuyk et al., 1992). During slaughter without stunning, the eyelash reflex is generally lost after the loss of corneal reflex (personal observations), suggesting that it is more resistant to the effects of anoxia. Compared to the corneal reflex, it may be more difficult to standardize the palpebral and eyelash test in the slaughter context and the exact interpretation of their presence or absence needs further studies.

The nictitating membrane or third eyelid is a transparent eyelid present in many birds, reptiles, amphibians and fish, but also in some mammals such as rabbits. It moves horizontally below the outer lid. This membrane also closes in response to touching the cornea. The neuronal circuit is partially similar to that described for the corneal reflex (Desmond, Rosenfield, \& Moore, 1983). Following electrical stunning,

${ }^{2}$ Following a local haemorrhage or tumour for example. the external eyelids close but the third eyelid remains open. In birds and possibly other species possessing a third eyelid we can test the corneal reflex even if external eyelids are closed: by touching the corner of the eye it is possible to visually observe or to feel underneath the fingers, the closing movement of the third eye lid (Erasmus, Turner, \& Widowski, 2010; Bourguet, Deiss \& Terlouw, personal observations).

The pupillary reflex corresponds to the contraction of the pupil when exposed to light and is an important evaluation for the prognosis of comatose patients (Thomas, 2000). The presence of mydriasis (dilated pupils) may be a useful indicator of a correct electrical stun in pigs (EFSA, 2004). The pupillary reflex necessitates however a functional condition of the retina. The neurological system involves the optic nerve (sensory information) and the oculomotor nerve (motor response). The integration centre is located in the midbrain, near the reticular formation. This reflex may be less adapted after the start of bleeding because the blood loss can reduce the functioning of the retina (Blackman, Cheetham, \& Blackmore, 1986). Blood covering the cornea may also reduce the feasibility of the test.

In summary, as indicated above, in the slaughter context, the corneal reflex is considered the most reliable eye reflex to evaluate the state of unconsciousness, but should be associated with other indicators of unconsciousness.

\subsection{Indicators with low discriminatory power or needing further development}

\subsubsection{Muscle tone}

Following an effective mechanical stun cattle collapse with the legs more or less bent, then after a few seconds, the front legs are stretched (Atkinson, Velarde, \& Algers, 2013). After an effective electrical stun, a collapsed sheep or pig is first rigid with the hind legs bent and front legs stretched, due to a general contraction of the muscles lasting 10 to $20 \mathrm{~s}$ (tonic phase). Subsequently, the animals show involuntary paddling movements for 15 to $60 \mathrm{~s}$ (clonic phase; Velarde et al., 2002). In birds the tonic phase is characterized by an extension of the legs, while the wings are pressed against the body and the neck is arched. The clonic phase is characterized by wing flapping. The body of an animal stunned by $\mathrm{CO}_{2}$ inhalation is relaxed first, but subsequently, muscle contractions can occur, especially in birds (Raj, Gregory, \& Wotton, 1990). Muscle tone is more difficult to use under field conditions, because physical movements evolve following the stun on the one hand, and incorrectly stunned animals may make movements that can be confounded with them, on the other (Terlouw et al., 2016).

\subsubsection{Eyeball rotation}

After captive bolt stunning, cattle that do not breathe and do not show a corneal reflex may present a rotation of the eyeball (Gregory et al., 2007; Terlouw et al., 2016). Even when eyeball rotation is present at the same time as signs of unconsciousness, its presence indicates that there is a risk of a shallower depth of unconsciousness or a return of consciousness (Atkinson et al., 2013; Gregory et al., 2007). Taking into account the degree of the rotation may improve its discriminatory power. One study showed that the presence of a full rotation required a second stun, while a partial rotation required increased monitoring of the animal (Atkinson et al., 2013). During bleeding without stunning, eyeball rotation may occur while the animal is still conscious (Terlouw et al., personal observations). However, in the later stages following bleeding without stunning eye rotation may be associated with a state of profound unconsciousness (Grandin, 2013) ${ }^{3}$. This suggestion is consistent with the progressive increase of the proportion of cattle with rotating eyeballs following bleeding without stunning (Bourguet et al., 2011). ${ }^{4}$ Eyeball

\footnotetext{
3 http://www.grandin.com/ritual/kosher.box.variables.time.lose.sensibility.html.

4 The small proportion of animals with a rotation of the eyeballs in this study can be explained by the observation method using scan sampling, which is less adapted to shortlasting behavioural expressions than the continuous observation method.
} 
Table 2

Examples of delays of loss of appearance of indicators of the state of unconsciousness and behavioural signs after direct bleeding or stunning.

\begin{tabular}{|c|c|c|c|c|c|c|}
\hline \multicolumn{7}{|c|}{ Studies on the loss of consciousness: calves (delays in s) } \\
\hline Ref. $^{\text {a }}$ & $\begin{array}{l}\text { First sign of abnormal } \\
\text { EEG }\end{array}$ & Loss of corneal reflex & Permanent abnormal EEG & Isoelectric EEG & End of gasps & \\
\hline 1 & $70 \pm 6$ & $187 \pm 25$ & $197 \pm 22$ & $225 \pm 27$ & $311 \pm 26$ & \\
\hline 2 & $75 \pm 46$ & - & $164 \pm 17$ & $183 \pm 17$ & $193 \pm 56$ & \\
\hline \multicolumn{7}{|c|}{ Studies on the loss of consciousness: poultry (delays in s) } \\
\hline Ref. & Permanent eye closure & $\begin{array}{l}\text { Start and end of intensive } \\
\text { wing flapping }\end{array}$ & Respiratory arrest & $\begin{array}{l}\text { Start and end of weak } \\
\text { wing flapping }\end{array}$ & Loss of corneal reflex & $\begin{array}{l}\text { Loss of muscle tone in the } \\
\text { neck }\end{array}$ \\
\hline 3 & $8 \pm 3$ & $10 \pm 1 ; 29 \pm 5$ & $22 \pm 10$ & $29 \pm 4 ; 78 \pm 10$ & $36 \pm 8$ & $81 \pm 4$ \\
\hline Ref. & $\begin{array}{l}\text { Reduction of EEG } \\
\text { power }\end{array}$ & Loss of evoked potentials & Permanent eye closure & $\begin{array}{l}\text { Start and end of clonic } \\
\text { phase } \\
\text { (wing flapping) }\end{array}$ & $\begin{array}{l}\text { Start and end of tonic phase } \\
\text { (extension of the wings and } \\
\text { legs) }\end{array}$ & Isoelectric EEG \\
\hline 4 & $21 \pm 4$ & $30 \pm 2$ & $34 \pm 5$ & $45 \pm 4 ; 60 \pm 5$ & $68 \pm 10 ; 85 \pm 7$ & $101 \pm 18$ \\
\hline \multicolumn{7}{|c|}{ Studies on the return of consciousness: pigs and calves (ref. 5: \% of pigs, refs. 6 and $7:$ delays in s) } \\
\hline Ref. & Corneal reflex & Spontaneous blinking & Eye pursuit & Nose twitch & Righting reflex & Rhythmic breathing \\
\hline 5 & 93.8 & 40.8 & 32.7 & 32.7 & 14.3 & 12.2 \\
\hline Ref. & End of tonic phase & End of epileptiform EEG & End of clonic phase & Return of corneal reflex & Return of rhythmic breathing & Head righting reflex \\
\hline 6 & $9 \pm 0.8$ & $36 \pm 4.9$ & $34 \pm 3.3$ & $37 \pm 3.0$ & $44 \pm 2.0$ & $59 \pm 3.8$ \\
\hline Ref. & End of tonic phase & End of clonic phase & $\begin{array}{l}\text { Return of rhythmic } \\
\text { breathing }\end{array}$ & Return of corneal reflex & Head righting reflex & \\
\hline 7 & $11 \pm 0.1$ & $22 \pm 1$ & $25 \pm 1$ & $67 \pm 8$ & $67 \pm 7$ & \\
\hline
\end{tabular}

a References: Ref. 1: Newhook and Blackmore, 1982; 8 calves, slaughter without stunning; Ref. 2: Blackmore et al., 1983; 3 calves, bleeding without stunning; Ref. 3: Bourguet et al., 2012

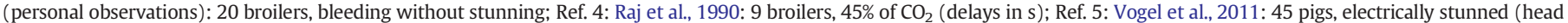

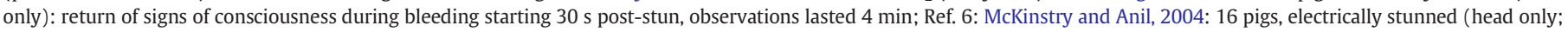
200 V, 3 s); Ref. 7. Gregory et al., 1996: 10 calves, electrically stunned (head only; 200 V, 3 s).

movements depend on 6 extraocular muscles that receive information from different lower brain centres including the oculomotor, trochlear and abducens nuclei, located in the pons and midbrain of the brainstem (Enderle, 2000; Tehovnik et al., 2000). These lower brain centres are controlled by higher brain centres (Enderle, 2000; Tehovnik et al., 2000). The mechanisms underlying the movements of the eyeballs after stunning and after the bleeding without stunning are not yet known.

\subsubsection{Nystagmus}

Nystagmus is a vertical or horizontal rapid oscillation of the eyeball due to repeated contractions of extraocular muscles. Nystagmus is indicative of damage to the underlying circuits in the brainstem, but may also result from damage to the cerebellum or the vestibular system (Hüfner et al., 2007). Nystagmus is considered as an indicator with low discriminatory power. A study by captive bolt stunning in cattle showed that nystagmus was rare (occurring in $3 \%$ of the animals) but when present, there was 1 in 3 chance that the quality of the stun was insufficient (Gregory et al., 2007). This estimate is consistent with other studies (Bourguet et al., 2011; Terlouw et al., 2016).

\subsubsection{Response to a painful stimulus}

To test the response to a pain stimulus, the withdrawal response following a pinch (of the comb, the ear tips, or the nasal septum for example), a skin prick with a hypodermic needle, or spraying with hot water may be tested (Limon et al., 2010; McKinstry \& Anil, 2004; Parotat, von Holleben, Arnold, Troeger, \& Luecker, 2015; Verhoeven et al., 2015b). Currently, the pain test needs further research to improve its discriminatory power. Certain responses to painful stimuli require cortical input and are indicative of consciousness. Other responses to painful stimuli may be simple nociceptive arc-reflex responses, based on a circuit involving the spinal cord, but not the brain. For example, in the study of Terlouw et al. (2016), some cattle showed a movement of the neck in the ventral direction in response to the cutting of the skin and blood vessels when bleeding the animal. This reaction was weaker in bulls following longer stun-stick intervals. This movement is most likely a nociceptive reflex response based on a neural circuit that passes through the spinal cord, but not the brain. The stronger response in bulls bled sooner after the stun indicates that the nerves involved in the arc-reflex response had still a degree of functionality. The reaction to the cut of skin and tissues can therefore not be used as an indicator of consciousness. Similarly, pharmacologically anaesthetised sheep showing an EEG indicative of unconsciousness responded to an ear pinch (Verhoeven et al., 2015b). Hence, certain pain responses are not necessarily indicative of consciousness.

Other studies show that a pain response may be an indicator of a certain degree of brainstem functioning. For example, in a majority of

Table 3

Correlations ( $\mathrm{r}$-values) between various indicators of the progressive installation of unconsciousness after direct bleeding. According to data of 8 calves in Newhook \& Blackmore (1982).

\begin{tabular}{|c|c|c|c|c|}
\hline \multirow[b]{2}{*}{ Delay until } & \multicolumn{4}{|l|}{ Delay until } \\
\hline & Loss of corneal reflex & Permanent abnormal EEG & Isoelectric EEG & End of gasping \\
\hline First abnormality in the EEG $(70.0 \pm 6.3 \mathrm{~s})$ & 0.41 & 0.26 & 0.29 & 0.31 \\
\hline Loss of corneal reflex & & $0.85^{* *}$ & 0.59 & $0.75^{*}$ \\
\hline Permanent abnormal EEG & & & $0.83^{*}$ & $0.64^{+}$ \\
\hline Isoelectric EEG & & & & $0.75^{*}$ \\
\hline
\end{tabular}

\footnotetext{
$+\mathrm{p}<0.10$

$* \mathrm{p}<0.05$.

** $\mathrm{p}<0.01$.
} 
Delay until permanent presence of EEG incompatible with consciousness (s)

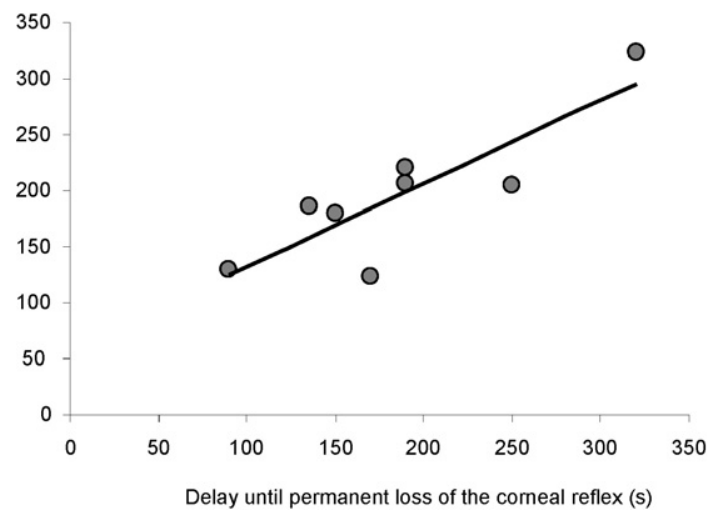

Fig. 1. Correlation between the delay until abolition of the corneal reflex and the appearance of EEG incompatible with consciousness. According to data of Newhook \& Blackmore (1982).

calves bled without stunning, the pain response was lost several seconds before their EEG indicated unconsciousness (Verhoeven et al., 2016). In another study, after stunning and sticking, certain pigs moved when they received a nociceptive stimulus due to a hot water spray. These same pigs showed also eyelid closure upon touching the cornea or when a light was shone in the eye, suggesting that the response to the hot water spray was indicative of a certain degree of brainstem functioning (Parotat et al., 2015). The interest of the test is that it can be automatized.

Further studies are needed to evaluate the exact relationships between various nociceptive stimuli and brain functioning. For example, in the above study, the same pigs were also tested using a nasal septum pinch but only one third of the pigs that moved when they received the hot water spray responded to the nasal septum pinch (Parotat et al., 2015). Similarly, immediately following a neck cut of non-stunned sheep, the withdrawal response to an ear pinch was lost, while breathing and the corneal reflex were still present and the EEG indicated the presence of consciousness (Verhoeven et al., 2015b). These results suggest that in the slaughter context, certain stimuli may not be strong enough to evoke a reaction or possibly, that certain animals or species are physically unable to respond.

In conclusion, a response to a painful stimulus may either involve only the spinal cord and thus represent a nociceptive reflex, or involve higher brain centres and thus be indicative of a certain degree of consciousness. Similarly, the absence of a response is not always indicative of unconsciousness. These recent results are promising but further research is needed to fully explore the relationship between reactions to different pain stimuli and brain functioning, while aiming for tests that aim to cause as little pain as possible (Parotat et al., 2015).

\subsubsection{Response to sensory stimuli other than threat or pain}

Certain responses to sensory stimuli are expected to require cortical input and to be indicative of consciousness. In addition to the threat and pain test discussed above, other tests involving sensory stimuli include withdrawal responses to an air blow in the nostrils, ear movements in response to a hand clap, or a movement of the nostrils or of the tongue in response to odours or flavours, respectively. In a group of cattle having undergone puntilla and of which $82 \%$ showed rhythmic breathing, only 11 and $20 \%$ responded to a needle prick and a stick in the nostril, respectively (Limon et al., 2010). Between 4 and 39\% of these animals responded to odours or flavours of molasses, lemon, vinegar, and salt and $21 \%$ to a hand clap near the ear (Limon et al., 2010). These low percentages indicate much lower discriminatory power for these tests than for the threat test, but further research is needed including other slaughter procedures and species.

\subsubsection{Apparently spontaneous neck or leg movements after stunning}

Following stunning or following bleeding without stunning, animals present frequently paddling, neck, back or wing movements that are not associated with the clonic phase following electrical stunning (Grandin, 2013). A study shows that paddling in correctly stunned cattle is most likely an involuntary movement linked to rhythm-generating centres of the brainstem structures and the spinal cord (Terlouw et al., 2016) involved in the production of rhythmic motor movements, such as walking (Guertin, 2009; Frigon, 2012). The functioning of these generators is independent of consciousness.

Lateral neck movements are difficult to interpret. Profoundly unconscious stunned cows may frequently show neck movements (Bourguet et al., 2011; Terlouw et al., 2016). However, in bulls, only animals showing ocular signs (nystagmus, rotating eyeballs, spontaneous blinking) or breathing, showed neck movements Terlouw et al., 2016. None of the bulls showed a corneal reflex, which would suggest that these animals were unconscious. Results suggest that following the stun, the extent of affected areas or type of structures damaged influences behavioural expression, even if the animals are correctly stunned.

In summary, at slaughter, it is essential to use a multi-criteria approach to verify indicators of consciousness and unconsciousness. Standing posture and voluntary vocalizations are signs of consciousness and must be absent. The absence of reflexes and eye movements, and the absence of rhythmic breathing are key signs of unconsciousness. The corneal reflex is generally regarded as the reference ocular reflex. If it is abolished and there is a permanent loss of the standing posture and no rhythmic breathing, then it is considered that the animal is stunned effectively.

Certain indicators, such as nystagmus, have low discriminatory power and its presence requires the verification of other indicators as well as increased monitoring of the animal until death.

\section{Relationships between the different indicators}

The localisation of different brain structures and their resistance to anoxia may explain the order in which different functions are lost. In humans, during the process evolving towards brain death following neurological trauma, loss of functions occurs in the rostrocaudal direction: the medulla of the brainstem is often the last structure to lose its functions (Wijdicks, 2001). In the slaughter context, the order of loss of functions varies depending on the species, the techniques used and the indicators observed (Table 2). There are however some consistencies in the disappearance and appearance of certain indicators. For example, during the gassing of chickens, loss of the standing posture occurs on average 6-10 s before closing the eyes (Raj \& Gregory, 1990; Raj et al., 1990; Deiss, personal communication). In calves bled without stunning, the abolition of the corneal reflex preceded on average $10 \mathrm{~s}$ permanent abnormal EEG, in a fairly reliable manner and gasping stopped after the EEG had become isoelectric (Table 2; Blackmore, Newhook, \& Grandin, 1983; Newhook \& Blackmore, 1982). In other studies on calves bled without stunning, the corneal reflex was abolished between 55 and $126 \mathrm{~s}$ after the EEG indicated unconsciousness (Lambooij, van der Werf, Reimert, \& Hindle, 2012; Verhoeven et al., 2016). In sheep bled without stunning, loss of the threat reflex occurred on average $8 \mathrm{~s}$ before, irregular breathing $28 \mathrm{~s}$ after, and absence of the palpebral reflex $59 \mathrm{~s}$ after the EEG indicated a state of unconsciousness (Verhoeven et al., 2015b). Hence, when sheep or cattle are bled without stunning, average delays indicate that events occur in the order: loss of response to threat, abnormal EEG indicative of unconsciousness, loss of rhythmic breathing, loss of palpebral reflex and loss of corneal reflex. After mechanical stunning of cattle, rotation of the eyeballs or rhythmic breathing is more frequently present than the corneal reflex (Gregory et al., 2007; Terlouw et al., 2016). These results may indicate that the corneal reflex is often 
Table 4

Correlations between different indicators relative to epileptic seizure and return of consciousness.

According to data on adult cattle by Wotton et al. (2000).

\begin{tabular}{|c|c|c|c|c|c|}
\hline \multirow{2}{*}{ Mean values $\rightarrow$} & $\begin{array}{l}\text { Duration of tonic } \\
\text { phase } \\
12.7 \pm 1.3 \mathrm{~s}\end{array}$ & $\begin{array}{l}\text { Duration of clonic } \\
\text { phase } \\
43.9 \pm 5.8 \mathrm{~s}\end{array}$ & $\begin{array}{l}\text { Total duration of tonic }+ \\
\text { clonic phases } \\
56.6 \pm 5.8 \mathrm{~s}\end{array}$ & $\begin{array}{l}\text { Delay until return of rhythmic } \\
\text { breathing } \\
53.6 \pm 4.6 \mathrm{~s}\end{array}$ & $\begin{array}{l}\text { Delay until return of } \\
\text { standing posture } \\
132.6 \pm 16.5 \mathrm{~s}\end{array}$ \\
\hline & r-Value & r-Value & r-Value & r-Value & r-Value \\
\hline Intensity of current received (mean $1.3 \pm 0.06 A$ ) & $-0.54^{*}$ & 0.22 & 0.07 & -0.15 & 0.21 \\
\hline Duration of tonic phase & & -0.04 & 0.19 & 0.43 & 0.09 \\
\hline Duration of clonic phase & & & $0.97^{* * *}$ & $0.76^{* *}$ & $0.78^{* *}$ \\
\hline Total duration of tonic + clonic phases & & & & $0.86^{* * *}$ & $0.55^{*}$ \\
\hline Delay until return of rhythmic breathing & & & & & $0.60^{*}$ \\
\hline
\end{tabular}

* $\mathrm{p}<0.05$.

** $\mathrm{p}<0.01$.

*** $\mathrm{p}<0.001$

lost before abolishment of breathing or rotation of the eyeballs. In a study on gas stunning in pigs, it was found that the presence of spontaneous blinking was an indicator of a high risk of an inadequate stun and in the absence of spontaneous blinking, the presence of a corneal reflex an indicator of a high risk of recovery. Pigs presenting spontaneous blinking, regular or difficult breathing presented always at least one other indicator, whether considered discriminatory or not (Atkinson et al., 2012; Fig. 2).

Data exist also on the order of re-appearance of indicators during recovery. In pigs, during the return of consciousness after reversible electrical stunning, recovery of corneal reflex occurs before resumption of breathing (McKinstry \& Anil, 2004; Vogel et al., 2011). However, in calves, the opposite was observed (Gregory, Anil, McKinstry, \& Daly, 1996).

Thus, abolition of the corneal reflex and respiratory arrest are considered important indicators of the unconsciousness of the animal because in principle they occur after the loss of consciousness. Moreover, the cessation of breathing induces or contributes to the anoxia of the

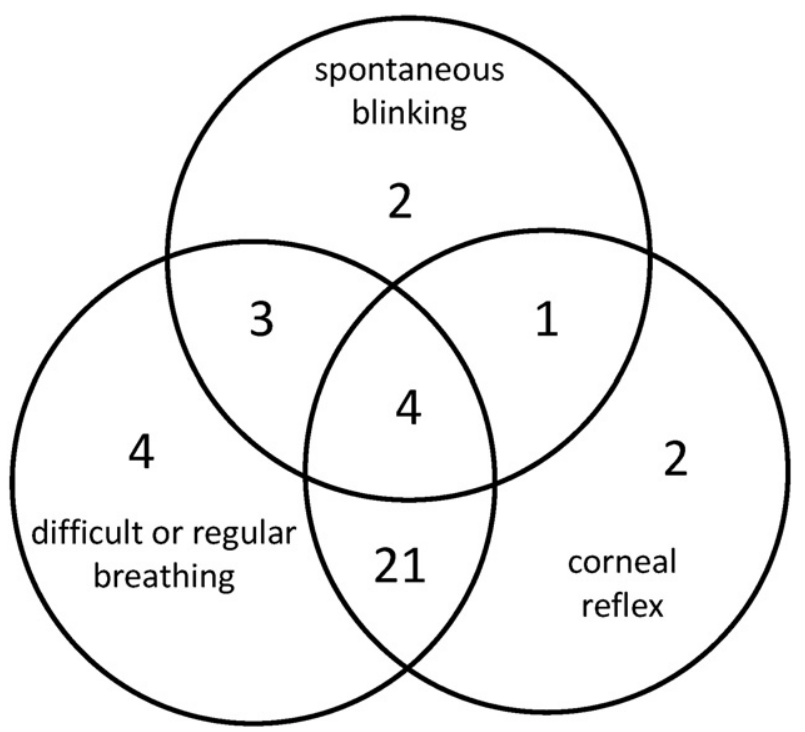

Fig. 2. Venn diagram of numbers of pigs presenting different indicators, following gas stunning in commercial abattoirs. Blinking: spontaneous eyelid closure; corneal reflex: eyelid closure in response to lightly touching the cornea; difficult or rhythmic breathing: opening the mouth apparently taking short gasps of air while flexing the head forwards more than 3 times within $10 \mathrm{~s}$ intervals or rhythmic air inhalation as shown by movements of the chest or flank. Pigs showing blinking were at a high risk of inadequate stunning. Pigs showing a corneal reflex were at a high risk of recovery. If regular kicking and convulsions are also taken into account as indicators (not shown), results showed that presence of spontaneous blinking or breathing was always associated with at least one other positive indicator.

After Atkinson et al. (2012). brain. Despite the importance of these indicators, in the context of slaughter, their precise relationships with the brain state or with other indicators of consciousness or unconsciousness are insufficiently known. They appear to depend on the species and/or type of stunning or slaughter technique used.

The study of relationships between different indicators of unconsciousness and consciousness may benefit from analyses by correlation. The data of Newhook and Blackmore (1982) show that the delays of appearance of various indicators were generally correlated (Table 3; Fig. 1). Similarly, analysis of data produced by Wotton, Gregory, Whittington, and Parkman (2000) on electrical stunning of adult cattle shows that the duration of the tonic phase depends on the amount of current received. The delays to recover a standing posture were correlated with the duration of the clonic phase and the delay until the resumption of breathing. For half of the animals, the return of respiration took place before the end of the clonic phase (Table 4). This type of analyses may help to increase our understanding of the relationships between indicators of unconsciousness and consciousness and the functional status of different parts of the brain.

Under field conditions, given the variability of the results in terms of delay until induction of unconsciousness, operators must assess indicators of consciousness and unconsciousness of each animal until the end of bleeding. It is necessary to combine a maximum of indicators to achieve a diagnosis as reliable as possible. When in doubt, the operator must proceed as quickly to a second stun, and verify the stunning equipment.

\section{Estimated delay until brain death in the slaughter context}

It is difficult to know when exactly death occurs after bleeding. In humans, the exact criteria of the establishment of death vary by country

\section{Box 1}

Brainstem reflexes tested as a contribution to the diagnosis of unconsciousness or death in humans.

- Pupillary light: pupils reactive to light.

- Corneal: movement of the eyelid when the cornea is lightly touched.

- Oculo-cephalic: eyeball movement in the direction opposite to that of the head when it is suddenly rotated.

- Oculo-vestibular: eye movement after injection of the ear canals with ice water when the patient's head is placed at $30^{\circ}$ in the horizontal plane.

- Oro-pharyngeal: vomiting reflex when stimulating the posterior pharyngeal wall cough reflex when stimulating the endotracheal tube. 


\section{Box 2}

New technologies push away the threshold of death.

\begin{abstract}
The transition from life to death is not necessarily immediate; it is not an all-or-nothing phenomenon but a process that progressively leads to death (Laureys, 2005).

Until recently it was believed that more than 4 or 5 min of global and complete brain ischemia caused death or survival with severe negative consequences because the brain damage was irreversible (Allen \& Buckberg, 2012; Cole \& Corday, 1956; Madl \& Holzer, 2004). However, new techniques are developed, such as cardiopulmonary bypass and controlled perfusion of organs including the brain before the restoration of normal blood flow and before the resumption of normal cardiac activity. Under experimental conditions, in pigs, the use of these techniques allowed cerebral resuscitation without sequelae after 10-15 min of cardiac arrest and after $30 \mathrm{~min}$ of complete global brain ischemia (Allen, Ko, Buckberg, \& Tan, 2012; Liakopoulos et al., 2010; Nichol, KarmyJones, Salerno, Cantore, \& Becker, 2006; Trummer et al., 2010). These results do not change the definition of brain death, in many countries defined as the irreversible and permanent cessation of the functioning of brain structures responsible for vital functions like breathing and thermal and cardiovascular regulation located in the brainstem (Laureys, 2005). They ask, however, the question of the definition of "irreversibility".
\end{abstract}

but involve the absence of signs of life ${ }^{5}$ : persistent cardiac and respiratory arrest, the total absence of consciousness and spontaneous motor activity (excluding spinal reflexes), the abolition of all brainstem reflexes (Box 1) and the absence of spontaneous breathing (French Public Health Code, Article R1232-1). The absence of confounding factors (drugs, hypothermia, etc.) must be ensured (Wijdicks, 2001). Confirmatory testing (EEG, angiography, brain tomography) showing the absence of electrical activity, blood flow, metabolic activity (Laureys, 2005) and of a ventilatory reflex (hypercapnic test, ${ }^{6}$ Wijdicks, 2001) may be necessary. ${ }^{7}$ It should be noted that the signs of life are at different levels: while cardiac arrest and respiratory arrest are likely to induce death, lack of awareness and lack of brainstem reflexes are the consequences.

The diagnosis of death as performed in humans cannot be carried out in the slaughter context for technical and practical reasons. When death is not caused by brain damage due to the stun, it is induced by a lack of oxygen supply to the brain, often associated with a lack of nutrient supply, due to cardiac and/or respiratory arrest, or exsanguination. Cardiac and/or respiratory arrest can be difficult to diagnose with certainty in the abattoir. It is however possible to estimate the average delay until death, relative to the end of bleeding. In humans, after cardiac arrest, the chances of survival depend on the delay until cardiopulmonary resuscitation. When this occurs in less than 4 to $5 \mathrm{~min}$, the chances of survival are two times greater than when it takes place between 5 and 8 min (Cole \& Corday, 1956; Hornby, Hornby, \& Shemie, 2010; Larsen, Eisenberg, Cummins, \& Hallstrom, 1993; Waalewijn, De Vos, Tijssen, \& Koster, 2001; Weston, Jones, \& Wilson, 1997). In addition, humans who were not resuscitated within 5 min following cardiac arrest suffer almost always serious heart and brain damage (Cole \& Corday, 1956; Hornby et al., 2010). In pigs resuscitated after cardiac

\footnotetext{
5 The signs of death can only be recognized at a later stage: lowered body temperature, rigor mortis (stiffness), livor mortis (purple-red skin discoloration), dehydration (clouding of the cornea, for example), putrefaction.

${ }^{6}$ Induction of blood $\mathrm{pCO}_{2}$ of $60 \mathrm{~mm} \mathrm{Hg}$, or $20 \mathrm{~mm} \mathrm{Hg}$ above the normal values

According to the French public health code, if the person whose death is recognized clinically, is assisted by mechanical ventilation and maintains haemodynamic functioning, the absence of spontaneous breathing is verified by a hypercapnia test (absence of breathing in response to a given amount of $\mathrm{CO}_{2}$ in the blood) and confirmatory tests ( 2 EEGs at a 4 hour interval or angiography; the public Health Code Article R1232-2).
}

arrest of up to $4.5 \mathrm{~min}$, electrical brain activity reappeared. If resuscitation took place after 5 min or more electrical brain activity remained absent. Brain stem reflexes were present up to 5 min of cardiac arrest (Stiegler, Sereinigg, Puntschart, Seifert-Held et al., 2012). If we transpose this information to livestock, disregarding the possible consequences of the stun, it is likely that 4 to $5 \mathrm{~min}$ after the end of bleeding the animal is deeply unconscious or dead, even when the bleeding was carried out on a non-stunned animal (Hornby et al., 2010; Stiegler et al., 2012; but see Box 2).

\section{Conclusion}

This second review aims to contribute to the reflection on the use and interpretation of indicators of consciousness and unconsciousness. Indicators of consciousness and unconsciousness are tools to assess indirectly the state of brain function. Their diversity allows evaluating different aspects of the state of consciousness, related to its contents (e.g. the presence of eye pursuit indicates that the animal integrates information from the environment) and level (e.g. the absence of the corneal reflex indicates a priori that the level of wakefulness is zero). As the indicators are only indirectly related to the state of consciousness, it is necessary to check several. A state of unconsciousness is diagnosed when the signs of consciousness are absent and those of unconsciousness are present. When after a stun, all indicators do not concur to establish that the animal is unconscious it is necessary to proceed to a second stun. In abattoirs, since a state of unconsciousness may be reversible, monitoring of the animal must be continued until the end of bleeding.

The death certification procedures used for humans are not applicable in the slaughter context. The European Regulation requires, however, that dressing or scalding is carried out only after verification of the absence of signs of life (council regulation (EC) No 1099/2009). Under field conditions, this rule is adapted to the slaughter context: after bleeding, it is verified that the animal is not breathing, shows no brainstem reflexes and is bled properly. If these three points are confirmed in the context of the abattoir and at this stage of slaughter, the loss of vital functions is irreversible because the animal is completely bled and it can therefore be considered dead.

The implementation of Council Regulation No. 1099/2009 significantly improves procedures that aim to assess routinely the state of consciousness/unconsciousness of animals during the slaughter process. However, progress is still necessary and today's needs seem to be of two kinds. First, a clarification of certain terms and concepts related to the regulation is required. For example, it is important to distinguish clearly the concepts of death, cardiac arrest and absence of signs of life. Similarly, in this review we used the two terms, absence of signs of consciousness and presence of signs of unconsciousness, depending on their relationship to consciousness and unconsciousness. Both terms are used in various texts, including Council Regulation No. 1099/2009 (see EFSA, 2013; Gregory et al., 2010; Verhoeven et al., 2015a; Von Holleben et al., 2010). Their exact meaning is not always made explicit, and a more harmonized and consensual use of such terms would facilitate exchanges of ideas. Second, it is necessary to continue research efforts on the interpretation of indicators related to consciousness and unconsciousness, their relationships with different types of brain damage and the reliability of their interpretation in terms of consciousness. Such knowledge would help to confirm or refine the methods of assessment of the state of consciousness of animals and reduce risks of misdiagnosis.

\section{Acknowledgements}

An earlier version of this review was published in French, in "Viande et Produits Carnés" in March 2015 (http://www.viandesetproduitscarnes.fr/ phocadownload/vpc_vol_31/3123_terlouw_aspects_neurobio_abattage_ 
partie_2.pdf). The authors thank the referees for their relevant and helpful comments that allowed us to improve the review.

\section{References}

Allen, B. S., \& Buckberg, G. D. (2012). Studies of isolated global brain ischaemia: I. Overview of irreversible brain injury and evolution of a new concept - Redefining the time of brain death. European Journal of Cardiothoracic Surgery, 41, 1132-1137.

Allen, B. S., Ko, Y., Buckberg, G. D., \& Tan, Z. (2012). Studies of isolated global brain ischaemia: II. Controlled reperfusion provides complete neurologic recovery following 30 min of warm ischaemia - the importance of perfusion pressure. European Journal of Cardiothoracic Surgery, 41, 1147-1154.

Anil, M. H. (1991). Studies on the return of physical reflexes in pigs following electrical stunning. Meat Science, 30(1), 13-21.

Aramideh, M., \& Ongerboer de Visser, B. W. (2002). Brainstem reflexes: Electrodiagnostic techniques, physiology, normative data, and clinical applications. Muscle $\mathcal{E}$ Nerve, 26(1), 14-30.

Atkinson, S., Velarde, A., \& Algers, B. (2013). Assessment of stun quality at commercia slaughter in cattle shot with captive bolt. Animal Welfare, 22(4), 473-481.

Atkinson, S., Velarde, A., Llonch, P., \& Algers, B. (2012). Assessing pig welfare at stunning in Swedish commercial abattoirs using $\mathrm{CO}_{2}$ group-stun methods. Animal Welfare, 21(4), 487-495.

Blackman, N. L., Cheetham, K., \& Blackmore, D. K. (1986). Differences in blood supply to the cerebral cortex between sheep and calves during slaughter. Research in Veterinary Science, 40(2), 252-254.

Blackmore, D. K., \& Newhook, J. C. (1982). Electroencephalographic studies of stunning and slaughter of sheep and calves - Part 3: The duration of insensibility induced by electrical stunning in sheep and calves. Meat Science, 7, 19-28.

Blackmore, D. K., Newhook, J. C., \& Grandin, T. (1983). Time of onset of insensibility in four- to six-week-old calves during slaughter. Meat Science, 9, 145-149.

Blumenfeld, H. (2002). Neuroanatomy through clinical cases. Sinauer Associates, Inc.

Bour, L., Ongerboer de Visser, B., Aramideh, M., \& Speelman, J. (2002). Origin of eye and eyelid movements during blinking. Movement Disorders, 17(Suppl. 2), 30-32.

Bourguet, C., Deiss, V., Tannugi, C. C., \& Terlouw, E. M. C. (2011). Behavioural and physiological reactions of cattle in a commercial abattoir: Relationships with organisationa aspects of the abattoir and animal characteristics. Meat Science, 88(1), 158-168.

Cole, S. L., \& Corday, E. (1956). Four-minute limit for cardiac resuscitation. Journal of the American Medical Association, 161(15), 1454-1458.

Cruccu, G., \& Deuschl, G. (2000). The clinical use of brainstem reflexes and hand-muscle reflexes. Clinical Neurophysiology, 111(3), 371-387.

Cruccu, G. Leardi, M. G., Ferracuti, S., \& Manfredi, M. (1997). Corneal reflex responses to mechanical and electrical stimuli in coma and narcotic analgesia in humans. Neuroscience Letters, 222(1), 33-36.

Dauvergne, C., Ndiaye, A., Buisseret-Delmas, C., Buisseret, P., Vanderwerf, F., \& Pinganaud, G. (2004). Projections from the superior colliculus to the trigeminal system and facial nucleus in the rat. The Journal of Comparative Neurology, 478(3), 233-247.

Desmond, J. E., Rosenfield, M. E., \& Moore, J. W. (1983). An HRP study of the brainstem afferents to the accessory abducens region and dorsolateral pons in rabbit: Implications for the conditioned nictitating membrane response. Brain Research Bulletin, 10(6), 747-763.

Delgado-Garcia, J. M., Evinger, C., Escudero, M., \& Baker, R. (1990). Behavior of accessory abducens and abducens motoneurons during eye retraction and rotation in the alert cat. Journal of Neurophysiology, 64(2), 413-422.

Devinsky, O. (2004). Effects of seizures on autonomic and cardiovascular function Epilepsy Currents, 4(2), 43-46.

EFSA (2004). Welfare aspects of the main systems of stunning and killing the main commercial species of animals. The EFSA Journal, 45, 1-29.

EFSA (2013). Scientific opinion on monitoring procedures at slaughterhouses for bovines The EFSA Journal, 11(3460) (65 pages).

Enderle, J. D. (2000). The fast eye movement control system. the biomedical engineering handbook: second edition. In D. Joseph (Ed.), Bronzino Boca Raton: CRC Press LLC.

Erasmus, M. A., Turner, P. V., \& Widowski, T. M. (2010). Measures of insensibility used to determine effective stunning and killing of poultry. The Journal of Applied Poultry Research, 19(3), 288-298.

Frigon, A. (2012). Central pattern generators of the mammalian spinal cord. The Neuroscientist, 18(1), 56-69.

Gibson, T. J., Dadios, N., \& Gregory, N. G. (2015). Effect of neck cut position on time to collapse in halal slaughtered cattle without stunning. Meat Science, 110, 310-314.

Grandin, T. (1998). The feasibility of using vocalization scoring as an indicator of poor welfare during cattle slaughter. Applied Animal Behaviour Science, 56, 121-128.

Grandin, T. (2013). Recommended animal handling guidelines and audit guide: A systematic approach to animal welfare. AMI Foundation.

Gregory, N. G., Anil, M. H., McKinstry, J. L., \& Daly, C. C. (1996). Prevalence and duration of insensibility following electrical stunning in calves. New Zealand Veterinary Journal, $44(1), 1-3$.

Gregory, N. G., Fielding, H. R., von Wenzlawowicz, M., \& von Holleben, K. (2010). Time to collapse following slaughter without stunning in cattle. Meat Science 85(1), 66-69.

Gregory, N. G., Lee, C. J., \& Widdicombe, J. P. (2007). Depth of concussion in cattle shot by penetrating captive bolt. Meat Science, 77(4), 499-503.

Guertin, P. A. (2009). The mammalian central pattern generator for locomotion. Brain Research Reviews, 62(1) 45-56.

Hornby, K., Hornby, L., \& Shemie, S. D. (2010). A systematic review of autoresuscitation after cardiac arrest. Critical Care Medicine, 38(5), 1246-1253.

Hüfner, K., Stephan, T., Kalla, R., Deutschla, A., Wagner, J., Holtmannspo, M., ... Glasauer, S. (2007). Structural and functional MRIs disclose cerebellar pathologies in idiopathic downbeat nystagmus. Neurology, 69(11), 1128-1135.
Kaada, B. R., \& Jasper, H. (1952). Respiratory responses to stimulation of temporal pole, insula, and hippocampal and limbic gyri in man. A.M.A. Archives of Neurology and Psychiatry, 68(5), 609-619.

Kimura, J., \& Lyon, L. W. (1972). Orbicularis oculi reflex in the Wallenberg syndrome: Alteration of the late reflex by lesions of the spinal tract and nucleus of the trigeminal nerve. The Journal of Neurology, Neurosurgery, and Psychiatry, 35, 228-233.

Lambooij, E., van der Werf, J. T. N., Reimert, H. G. M., \& Hindle, V. A. (2012). Restraining and neck cutting or stunning and neck cutting of veal calves. Meat Science, 91(1), 22-28.

Larsen, M. P., Eisenberg, M. S., Cummins, R. O., \& Hallstrom, A. P. (1993). Predicting survival from out-of-hospital cardiac arrest: A graphic model. Annals of Emergency Medicine, 22(11), 1652-1658.

Laureys, S. (2005). Science and society: Death, unconsciousness and the brain. Nature Reviews Neuroscience, 6(11), 899-909.

Liakopoulos, O. J., Allen, B. S., Buckberg, G. D., Hristov, N., Tan, Z., Villablanca, J. P., \& Trummer, G. (2010). Resuscitation after prolonged cardiac arrest: Role of cardiopulmonary bypass and systemic hyperkalemia. Annals of Thoracic Surgery, 89(6), 1972-1979.

Limon, G., Guitian, J., \& Gregory, N. G. (2010). An evaluation of the humaneness of puntilla in cattle. Meat Science, 84(3), 352-355.

Liu, G. T., \& Ronthal, M. (1992). Reflex blink to visual threat. Journal of Clinical NeuroOphthalmology, 12(1), 47-56

Madl, C., \& Holzer, M. (2004). Brain function after resuscitation from cardiac arrest. Current Opinion in Critical Care, 10(3), 213-217.

McKinstry, J. L., \& Anil, M. H. (2004). The effect of repeat application of electrical stunning on the welfare of pigs. Meat Science, 67(1), 121-128.

Morcuende, S., Delgado-Garcia, J. -M., \& Ugolini, G. (2002). Neuronal premotor networks involved in eyelid responses: Retrograde transneuronal tracing with rabies virus from the orbicularis oculi muscle in the rat. Journal of Neuroscience, 22(20), 8808-8818.

Newhook, J. C., \& Blackmore, D. K. (1982). Electroencephalographic studies of stunning and slaughter of sheep and calves - Part 2: The onset of permanent insensibility in calves during slaughter. Meat Science, 6(4), 295-300.

Nichol, G., Karmy-Jones, R., Salerno, C., Cantore, L., \& Becker, L. (2006). Systematic review of percutaneous cardiopulmonary bypass for cardiac arrest or cardiogenic shock states. Resuscitation, 70(3), 381-394.

Ongerboer de Visser, B. W., \& Kuypers, H. G. (1978). Late blink reflex changes in lateral medullary lesions. An electrophysiological and neuro-anatomical study of Wallenberg's Syndrome. Brain, 101(2), 285-294.

Parotat, S., von Holleben, K., Arnold, S., Troeger, K., \& Luecker, E. (2015). Hot-water spraying is a sensitive test for signs of life before dressing and scalding in pig abattoirs with carbon dioxide $\left(\mathrm{CO}_{2}\right)$ stunning. Animal, 1-7.

Purves, D., Augustine, G. J., Fitzpatrick, D, Katz, L. C. A-S., LaMantia, A. S., McNamara, J. O., \& Williams, S. M. (Eds.). (2001). Motor control centers in the brainstem: Upper motor neurons thatmaintain balance and posture (Neuroscience, 4th ed.). Sunderland (MA): Sinauer Associates Available from: http://www.ncbi.nlm.nih.gov/books/NBK11081/.

Raj, A., \& Gregory, N. G. (1990). Effect of rate of induction of carbon dioxide anaesthesia on the time of onset of unconsciousness and convulsions. Research in Veterinary Science, 49 460-363.

Raj, A. B. M., Gregory, N. G., \& Wotton, S. B. (1990). Effect of carbon dioxide stunning on somatosensory evoked potentials in hens. Research in Veterinary Science, 49, 355-359.

Rossen, R. R., Kabat, H., \& Anderson, J. P. (1943). Acute arrest of cerebral circulation in man. Archives of Neurology and Psychiatry, 50(5), 510-528.

Schepens, B., \& Drew, T. (2004). Independent and convergent signals from the pontomedullary reticular formation contribute to the control of posture and movement during reaching in the cat. Journal of Neurophysiology, 92(4), 2217-2238.

Siegel, A., \& Sapru, H. N. (2006). The reticular formation, part 23. In A. Siegel, \& H. N. Sapru (Eds.), The neuron. Essential Neuroscience, Section IV. (pp. 427-444). Philadelphia, London/Tokyo, Hong Kong: Lippincott Williams and Wilkins.

Silbernagl, S., \& Despopoulos, A. (2003). Color atlas of physiology (5th ed.). Stuttgart, New York: Thieme.

St John, W. M. (2009). Noeud vital for breathing in the brainstem: Gasping-yes, eupnoea-doubtful. Philosophical Transactions of the Royal Society, B: Biological Sciences, 364, 2625-2633.

Stiegler, P., Sereinigg, M., Puntschart, A., Seifert-Held, T., Zmugg, G., Wiederstein-Grasser, I., ... Tscheliessnigg, K. (2012). A 10 min "no-touch" time - Is it enough in DCD? A DCD animal study. Transplant International, 25(4), 481-492.

Sturges, B. K. (2005). Neuro-ophthalmology: The visible nervous system. Proceedings of the 2nd Annual Veterinary Neurology Symposium. Davis - USA: University of California 2005.

Tatum, W. O. (2010). Atypical absence seizures, myoclonic, tonic and atonic seizures. In E. Wyllie, G. D. Cascino, B. E. Gidal, \& H. P. Goodkin (Eds.), Wyllie's treatment of epilepsy: Principles and practice (pp. 211). Philadelphia: Lippincott, Williams and Wilkins.

Tehovnik, E. J., Sommer, M. A., Chou, I. H., Slocum, W. M., \& Schiller, P. H. (2000). Eye fields in the frontal lobes of primates. Brain Research Reviews, 32(2-3), 413-448.

Terlouw, E. M. C., Bourguet, C., \& Deiss, V. (2016). Consciousness, unconsciousness and death in the context of slaughter. Part I. Neurobiological mechanisms underlying stunning and killing. Meat Science.

Terlouw, E. M. C., Bourguet, C., Deiss, V., \& Mallet, C. (2015). Origins of movements following stunning and during bleeding in cattle. Meat Science, 110, 135-144.

Thomas, P. D. (2000). The differential diagnosis of fixed dilated pupils: A case report and review. Critical Care and Resuscitation, 2(1), 34-37.

Trummer, G., Foerster, K., Buckberg, G. D., Benk, C., Heilmann, C., Mader, I., ... Beyersdorf, F. (2010). Successful resuscitation after prolonged periods of cardiac arrest: A new field in cardiac surgery. Journal of Thoracic and Cardiovascular Surgery, 139(5), 1325-1332.

Velarde, A., Ruiz-de-la-Torre, J. L., Rosello, C., Fabrega, E., Diestre, A., \& Manteca, X. (2002). Assessment of return to consciousness after electrical stunning in lambs. Animal Welfare, 11, 333-341. 
Verhoeven, M. T. W., Hellebrekers, L. J., Gerritzen, M. A., \& Kemp, B. (2016). Validation of indicators used to assess unconsciousness in veal calves at slaughter. Animal (in press).

Verhoeven, M. T., Gerritzen, M. A., Hellebrekers, L. J., \& Kemp, B. (2015a). Indicators used in livestock to assess unconsciousness after stunning: A review. Animal, 1-11.

Verhoeven, M. T. W., Gerritzen, M. A., Kluivers-Poodt, M., Hellebrekers, L. J., \& Kemp, B. (2015b). Validation of behavioural indicators used to assess unconsciousness in sheep. Research in Veterinary Science, 101, 144-153.

Vogel, K. D., Badtram, G., Claus, J. R., Grandin, T., Turpin, S., Weyker, R. E., \& Voogd, E. (2011). Head-only followed by cardiac arrest electrical stunning is an effective alternative to head-only electrical stunning in pigs. Journal of Animal Science, 89(5), 1412-1418.

Von Holleben, K., von Wenzlawowicz, M., Gregory, N., Anil, H., Velarde, A., Rodriguez, P., ... Lambooij, B. (2010). Report on good and adverse practices - Animal welfare concerns in relation to slaughter practices from the viewpoint of veterinary sciences, Dialrel Project. www.dialrel.eu/images/veterinary-concerns.pdf accessed 04/12/2015

Vuyk, J., Engbers, F. H. M., Lemmens, H. J. M., Burm, A. G. L., Vletter, A. A., Gladines, M. P. R. R., \& Bovill, J. G. (1992). Pharmacodynamics of propofol in female-patients. Anesthesiology, 77, 3-9.

Waalewijn, R. A., de Vos, R., Tijssen, J. G., \& Koster, R. W. (2001). Survival models for outof-hospital cardiopulmonary resuscitation from the perspectives of the bystander, the first responder, and the paramedic. Resuscitation, 51, 113-122.
Warriss, P. D., Brown, S. N., Adams, S. J., \& Corlett, I. K. (1994). Relationships between subjective and objective assessments of stress at slaughter and meat quality in pigs. Meat Science, 38(2), 329-340.

Watts, J. M., \& Stookey, J. M. (2000). Vocal behaviour in cattle: The animal's commentary on its biological processes and welfare. Applied Animal Behaviour Science, 67(1-2), 15-33.

Weston, C. F., Jones, S. D., \& Wilson, R. J. (1997). Outcome of out-of-hospital cardiorespiratory arrest in south Glamorgan. Resuscitation, 34(3), 227-233.

White, R. G., DeShazer, J. A., Tressler, C. J., Borcher, G. M., Davey, S., Waninge, A., .. Clemens, E. T. (1995). Vocalization and physiological response of pigs during castration with or without a local anesthetic. Journal of Animal Science, 73(2), 381-386.

Wijdicks, E. F. (2001). The diagnosis of brain death. New England Journal of Medicine, 344(16), 1215-1221.

Wotton, S. B., Gregory, N. G., Whittington, P. E., \& Parkman, I. D. (2000). Electrical stunning of cattle. Veterinary Record, 147(24), 681-684.

Zerari-Mailly, F., Dauvergne, C., Buisseret, P., \& Buisseret-Delmas, C. (2003). Localization of trigeminal, spinal, and reticular neurons involved in the rat blink reflex. Journal of Comparative Neurology, 467(2), 173-184. 